\title{
Coil Embolization in Patients with Recurrent Cerebral Aneurysms Who Previously Underwent Surgical Clipping
}

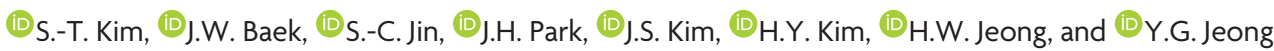

\begin{abstract}
BACKGROUND AND PURPOSE: Surgical revision of recurrent cerebral aneurysms is technically difficult. Therefore, coil embolization has been used as an alternative in these cases. The aim of this study was to evaluate the clinical and angiographic outcomes of coil embolization in patients with recurrent cerebral aneurysms after microsurgical clipping.
\end{abstract}

MATERIALS AND METHODS: Between May 1999 and February 2016, nineteen patients with 19 recurrent aneurysms who previously underwent surgical clipping were treated by coil embolization.

RESULTS: Nine patients presented with subarachnoid hemorrhage (47.4\%). The interval between surgical clipping and coil embolization was $143.5 \pm 66.1$ months (range, 43-276 months). Single- or double-catheter coil embolization was performed in 16 patients. A balloon ( $n=$ 1) and stents $(n=2)$ were used to assist the coil embolization in 3 patients. Immediate radiologic findings after coil embolization showed complete occlusion in 10 patients, a residual neck in 8 patients, and a residual sac in 1 patient. Procedure-related permanent morbidity occurred in 1 patient. The mean clinical follow-up was $58.3 \pm 38.8$ months. Poor clinical outcomes (modified Rankin Scale score $=\geq 3$ ) at the end of the clinical follow-up were reported in 5 patients (26.3\%). Angiographic follow-up was available for 12 patients (63.2\%). Major recurrence was detected in 5 patients (41.7\%), and a tendency for aneurysm regrowth rather than coil compaction was noted in all cases.

CONCLUSIONS: In our series, coil embolization for recurrent aneurysms after surgical clipping was feasible but had a high recurrence rate and tended to result in aneurysm regrowth rather than coil compaction.

ABBREVIATIONS: AcomA = anterior cerebral artery; PcomA = posterior communicating artery

M icrosurgical revision of recurrent cerebral aneurysms after surgical clipping is technically difficult because adhesions between the aneurysm and neighboring structures increase the possibility of injury to the adjacent normal structures. However, endovascular coil embolization, which does not require approaching the adhesions of previous surgical wounds, could be technically feasible as a retreatment option for recurrent cerebral aneurysms after surgical clipping. Some reports exist on the use-

Received July 17, 2018; accepted after revision October 10

From the Departments of Neurosurgery (S.-T.K., J.H.P., Y.G.J.) and Diagnostic Radiology (J.W.B., H.W.J.), Busan Paik Hospital, Inje University, College of Medicine, Busan, Republic of Korea; and Department of Neurosurgery (S.-C.J., J.S.K., H.Y.K.), Haeundae Paik Hospital, Inje University, College of Medicine, Busan, Republic of Korea.

Sung-Tae Kim and Jin Wook Baek contributed equally to this work.

This work was supported by a 2016 Inje University Busan Paik Hospital research grant.

Please address correspondence to Sung-Chul Jin, MD, Department of Neurosurgery, Inje University Haeundae Paik Hospital, 875, Haeun-daero, Haeundae-gu, Busan, 612-896, Republic of Korea; e-mail: kusmal@hanmail.com

三 Indicates article with supplemental on-line table.

http://dx.doi.org/10.3174/ajnr.A5909 fulness of coil embolization for recurrent cerebral aneurysms after surgical clipping. ${ }^{1-5}$ The durability of coil embolization of recurrent cerebral aneurysms previously treated by surgical clipping is not well-known. The aim of this study was to evaluate the clinical and angiographic outcomes of coil embolization in patients with recurrent cerebral aneurysms after microsurgical clipping.

\section{MATERIALS AND METHODS \\ Patients}

Between May 1999 and February 2016, nineteen patients (5 men and 14 women) with 19 recurrent cerebral aneurysms who had been primarily treated by surgical clipping were treated with endovascular coiling and included in our study. All recurrent aneurysms in our study showed morphologic changes in the aneurysms that had been treated by clipping. Residual aneurysms that showed no morphologic change on follow-up angiography after clipping were excluded from our study. The medical records and radiographic studies of these patients were retrospectively reviewed to obtain clinical and radiographic information. In cases of loss to clinical follow-up, we obtained the clinical status by 
telephone. This retrospective study was approved by the institutional review board (Inje University Haeundae Paik Hospital).

Clinical outcomes were measured before and after coiling, at discharge, and at the end point of clinical follow-up using the modified Rankin Scale score. Each patient's clinical status at the final clinical follow-up evaluation was recorded as the follow-up clinical outcome. The angiographic outcome was measured by the Raymond-Roy occlusion classification. ${ }^{6,7}$ In cases with a dometo-neck ratio of $<2$ or an aneurysm neck of $>4 \mathrm{~mm}$, the aneurysm was defined as a wide-neck aneurysm.

Recurrence of the aneurysms after coiling was classified as either regrowth of the aneurysms or coil compaction. "Regrowth" of aneurysms was defined as morphologic changes in the aneurysms in comparison with the initial angiographic morphology of the aneurysms. "Coil compaction" of the aneurysms was defined as changes in the coil configuration in comparison with the initial appearance of the coil mass after coil embolization without morphologic changes in the aneurysm. The classification of regrowth or coil compaction of the aneurysms was determined by 2 neuroradiologists (H.W.J. and J.W.B.).

Follow-up imaging studies generally consisted of conventional angiography because CTA or MRA had poor image resolution due to artifacts produced by the clips and coils. Angiography was generally performed annually after coil embolization, and the results were classified into 3 categories: stable or improved occlusion (defined as no change or a decrease of the residual aneurysm), minor recurrence (defined as regrowth or coil compaction of the aneurysmal neck portion), and major recurrence (defined as regrowth or coil compaction of the aneurysmal sac that required retreatment).

\section{Endovascular Strategies}

Coil embolization was performed with the patient under general anesthesia. A biplane angiographic unit was used. In cases of rupture, oral antiplatelet agents were not used before coil embolization, and intravenous heparin (a bolus of 3000 IU) was administered after the aneurysm was secured with the coil. In unruptured cerebral aneurysms, dual oral antiplatelet agents (75 mg of clopidogrel and $100 \mathrm{mg}$ of aspirin) were used for 5 days before coil embolization or a loading dose was administered (300 mg of clopidogrel and $300 \mathrm{mg}$ of aspirin). After attaining access to the femoral artery, a bolus of 3000 IU of heparin was administered intravenously at the beginning of the procedure. An additional 1000 -IU bolus of heparin was administered hourly to maintain an activated clotting time of $>250$ seconds. If an antiplatelet drug was necessary, aspirin (100 mg) or dual-antiplatelet agents (100 mg aspirin and $75 \mathrm{mg}$ clopidogrel) were administered for 3-6 months after coil embolization.

\section{Statistical Analysis}

The statistical analysis was performed using SPSS for Windows (Version 24; IBM, Armonk, New York). For the statistical analysis, the clinical outcome was dichotomized into good (mRS = $0-2)$ and poor outcomes ( $\mathrm{mRS}=3-6)$. The factors related to major recurrence after coil embolization were evaluated. Univariate analysis was performed with age (60 years or older versus younger than 60 years), sex, initial presentation, presentation at coil embolization, multiple aneurysms, aneurysm size, wide neck, procedural complications, rebleeding after coil embolization, stent-assisted embolization, clinical outcome, and immediate radiologic outcome as factors using the Fisher exact test due to the expected frequency. Variables with a value of $P<.2$ were included in the multivariate logistic regression analysis. Statistical significance was set at $P<.05$ for a $95 \%$ confidence interval.

\section{RESULTS}

The demographic characteristics, characteristics of aneurysms, clinical factors before coil embolization, and factors related to clinical and angiographic outcome are summarized in the On-line Table. The mean age of the patients included in our study was $61.4 \pm 9.3$ years, with a range of $45-76$ years. Seventeen patients initially presented with subarachnoid hemorrhage. All 19 patients had primarily undergone surgical clipping. At coil embolization, 9 patients $(47.4 \%)$ presented with SAH due to rerupture of an aneurysm that had been treated by surgical clipping, and 10 patients presented with unruptured aneurysms, which were detected as recurrence of the aneurysms. The locations of the aneurysms included the posterior communicating artery (PcomA, $n=$ $10)$, middle cerebral artery $(n=5)$, anterior communicating artery $(n=2)$, basilar tip $(n=1)$, and anterior choroidal artery $(n=$ $1)$. The mean size of aneurysms was $6.5 \pm 2.7 \mathrm{~mm}$, ranging from 3.3 to $12 \mathrm{~mm}$. The mean neck size was $4.9 \pm 2.2 \mathrm{~mm}$, ranging from 2.4 to $10 \mathrm{~mm}$. Seventeen aneurysms had a wide neck, and 9 patients had multiple aneurysms. The mean interval between clipping and coil embolization was $143.5 \pm 66.1$ months, ranging from 43 to 276 months. Coil embolization was performed using single or double catheters in 16 patients. A balloon $(n=$ $1)$ and stents $(n=2)$ were used to assist coil embolization in 3 patients. The 2 stent-assisted coil embolization aneurysms were located in the anterior communicating artery and PcomA, and the stents were Enterprise self-expanding stents (Codman \& Shurtleff, Raynham, Massachusetts).

A control angiogram obtained after coil embolization showed complete occlusion of the aneurysms in 10 patients, a residual neck in 8 patients, and a residual sac in 1 patient. Procedurerelated thromboembolic complications occurred in 2 patients, 1 of which resulted in permanent right hemiparesis (grade 3 ).

Angiographic follow-up was available for 12 patients (63.2\%). Among the other 7 patients who did not undergo cerebral angiography, 2 patients were in poor condition ( $m R S \geq 4)$, and the other 5 patients refused the procedure. Major recurrence was detected in 5 patients, resulting in a major recurrence rate of $41.7 \%(5 / 12)$.

At discharge, 9 patients had mRS scores of 0 , two patients had mRS scores of 1 , five patients had mRS scores of 2 , two patients had mRS scores of 4 , and 1 patient had an mRS score of 5 . The mean clinical follow-up after coil embolization was $58.3 \pm 38.8$ months and ranged from 3 to 181 months. The follow-up mRS scores were 0 in 10 patients, 1 in 1 patient, 2 in 3 patients, 3 in 1 patient, 4 in 2 patients, and 6 in 2 patients. Rebleeding developed in 2 patients at 18 and 180 months after coil embolization. All patients who had poor follow-up clinical outcomes $(\mathrm{mRS} \geq 3$ ) presented with SAH at coil embolization. Worsening of the mRS compared with the score at discharge after coil embolization occurred in 3 patients. One patient who had an aggravated clinical 
outcome after coil embolization was diagnosed with vascular dementia. Another patient exhibited rebleeding that caused clinical aggravation at 180 months after coil embolization. Another patient died due to sepsis caused by hospital-acquired pneumonia at the rehabilitation hospital.

Statistically significant results between major recurrence and the variables could not be achieved because of the small sample size. However, younger age $(P=.293)$ and SAH presentation at coil embolization $(P=.242)$ seemed to be somewhat related to major recurrence (Table 1$)$.

All 5 cerebral aneurysms that recurred after coil embolization showed aneurysm regrowth (Figs 1-5). All patients had initially presented with SAH at microsurgical clipping. Thereafter, 4 patients $(80 \%)$ presented with SAH due to aneurysm rerupture at coil embolization, and 1 patient underwent coil embolization due to regrowth of the aneurysm on serial follow-up angiography. Despite the risk of aneurysm regrowth, our endovascular strategy for ruptured cerebral aneurysms is considered a simple technique without flow diversion effect because of the possibility of procedural thromboembolism caused by insufficient antiplatelet medication. Additionally, we favor a simple technique as our endovascular strategy for unruptured cerebral aneurysms because stent-assisted coiling or flow diverters have shown insufficient evidence of procedural safety thus far. Therefore, we decided to retreat all patients by additional coil embolization using a simple technique without a stent (Table 2).

One patient, who had a PcomA aneurysm (patient 1), underwent additional coil embolization twice due to regrowth of the aneurysm at the 41st and 84th month after the primary coil embolization. Another patient who had a basilar tip aneurysm (patient 8) had a minor recurrence after additional coil embolization. Therefore, the patient was observed for 49 months after the primary coil embolization, and further follow-up seemed to be required. Two patients who experienced rebleeding events after coil embolization (patients 13 and 14) died or were bedridden after additional coil embolization. It took 180 months for rerupture of the middle cerebral artery aneurysm to occur after the primary coil embolization in 1 patient (patient 13) and 18 months for rerupture in another patient with a PcomA aneurysm (patient 14). The other patient who had a PcomA aneurysm (patient 16) underwent

Note:- mRS indicates modified Rankin scale.

${ }^{a}$ All $P$ values are significant.
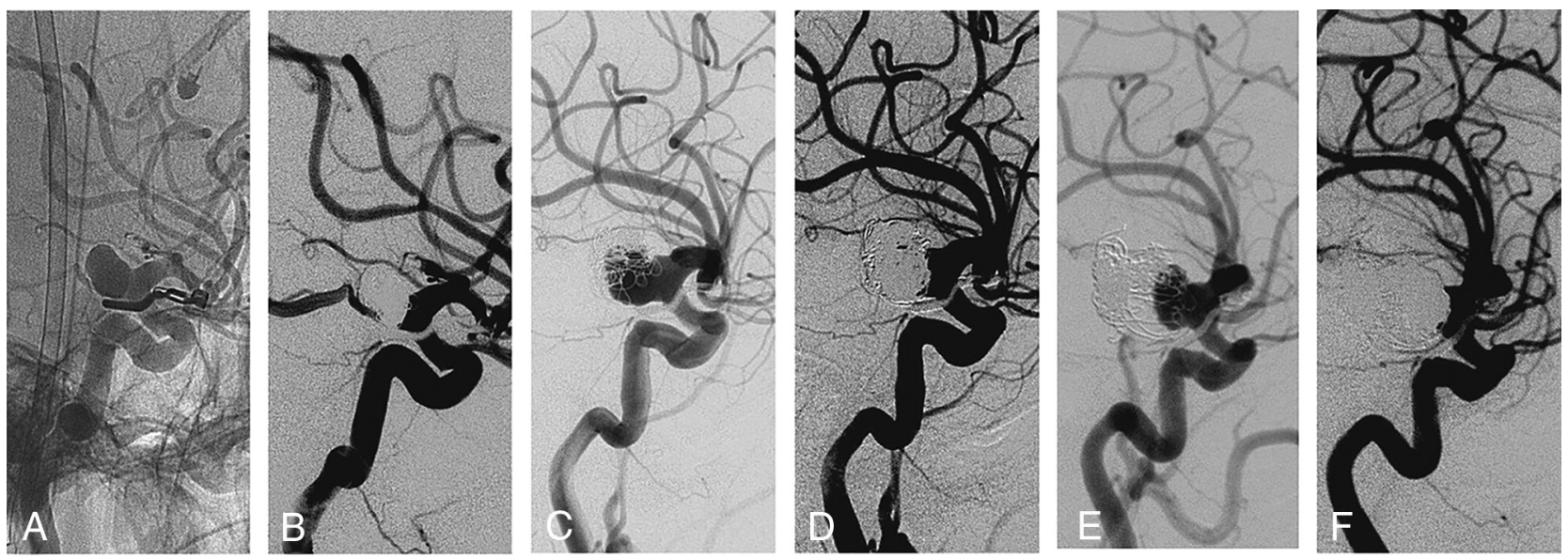

FIG 1. First case of our series, posterior communicating artery aneurysm. A, Working angle view angiography before the first coil embolization. $B$, After the first coil embolization, the final angiography evaluation reveals complete occlusion of the aneurysm. $C$, After 41 months, follow-up angiography reveals major recurrence of the aneurysm. $D$, After the second coil embolization, the residual neck is detected in the final angiography evaluation. E, After 43 months, follow-up angiography reveals major recurrence. $F$, Final image of the third coil embolization. 

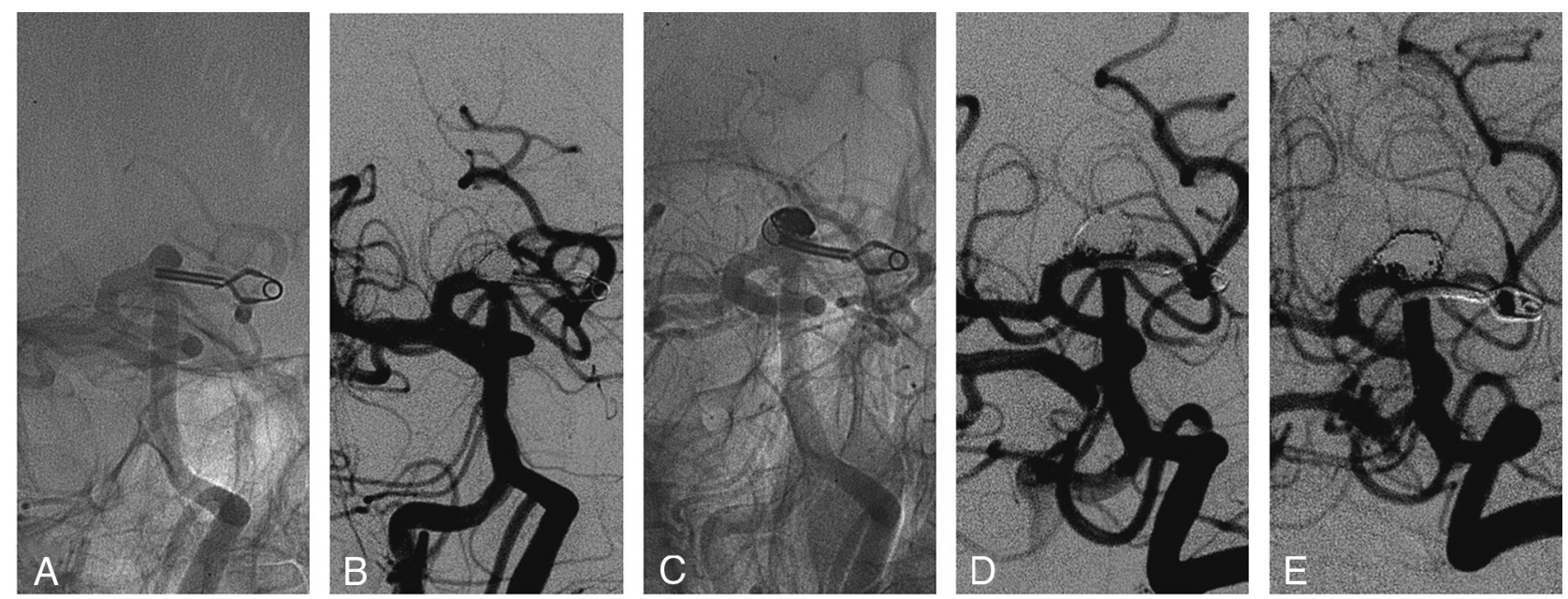

FIG 2. Eighth case of our series, basilar tip aneurysm. $A$, Working angle view angiography before first coil embolization. $B$, After the first coil embolization, the final angiography evaluation reveals complete occlusion of the aneurysm. C, After 29 months, follow-up angiography reveals major recurrence of the aneurysm. $D$, After the second coil embolization, the residual neck is detected in the final angiography evaluation. $E$, Follow-up angiography reveals minor recurrence.
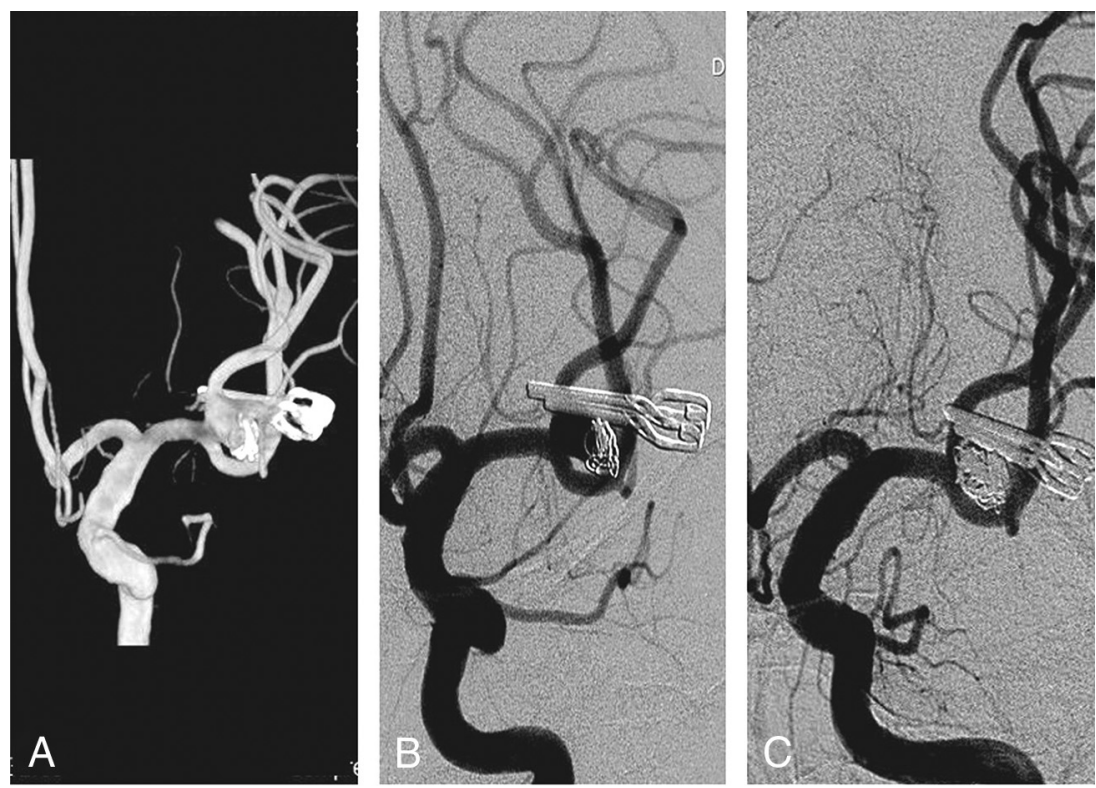

FIG 3. Thirteenth case in our series, left middle cerebral artery bifurcation aneurysm. The first coil embolization of this aneurysm was performed at another hospital. Therefore, we confirmed the presence of a residual neck in the medical record, without imaging. A, At 180 months after the first coil embolization, 3D rotational angiography reveals recurrence of a middle cerebral artery bifurcation aneurysm. $B$, Working angle angiography before the second coil embolization. $C$, The final angiography evaluation reveals complete occlusion of the aneurysm.

an additional coil embolization at 47 months after the primary coil embolization due to regrowth of the aneurysm.

\section{DISCUSSION}

Several reports on endovascular coiling for recurrent or residual cerebral aneurysms after microsurgical clipping have shown that the procedure is feasible. ${ }^{1-4}$ However, because recurrent cerebral aneurysms after surgical clipping may have more aggressive clinical and radiologic features than residual cerebral aneurysms after surgical clipping, we evaluated the radiologic and clinical outcomes of recurrent cerebral aneurysms after surgical clipping while excluding residual cerebral aneurysms.

In our series, procedural morbidity occurred in 1 case of thromboembolism (5.3\%), resulting in hemiparesis; no procedural mortal- ity occurred. Because there are no prospective-controlled studies, a direct comparison of the technical feasibility of revised microsurgical clipping and coil embolization is difficult for recurrent cerebral aneurysms treated by surgical clipping. However, considering previous reports on this issue, revised microsurgical clipping in this condition seems to be a complicated and an eventually challenging process. ${ }^{8,9}$ In addition, our procedural morbidity rate was not higher than that for the initial coil embolization of ruptured or unruptured cerebral aneurysms. ${ }^{7,10}$ Accordingly, coil embolization may be a feasible treatment option for recurrent cerebral aneurysms treated primarily by surgical clipping.

In our series, the recurrence and rebleeding rates of coil embolization for the recurrent cerebral aneurysms after microsurgi- 

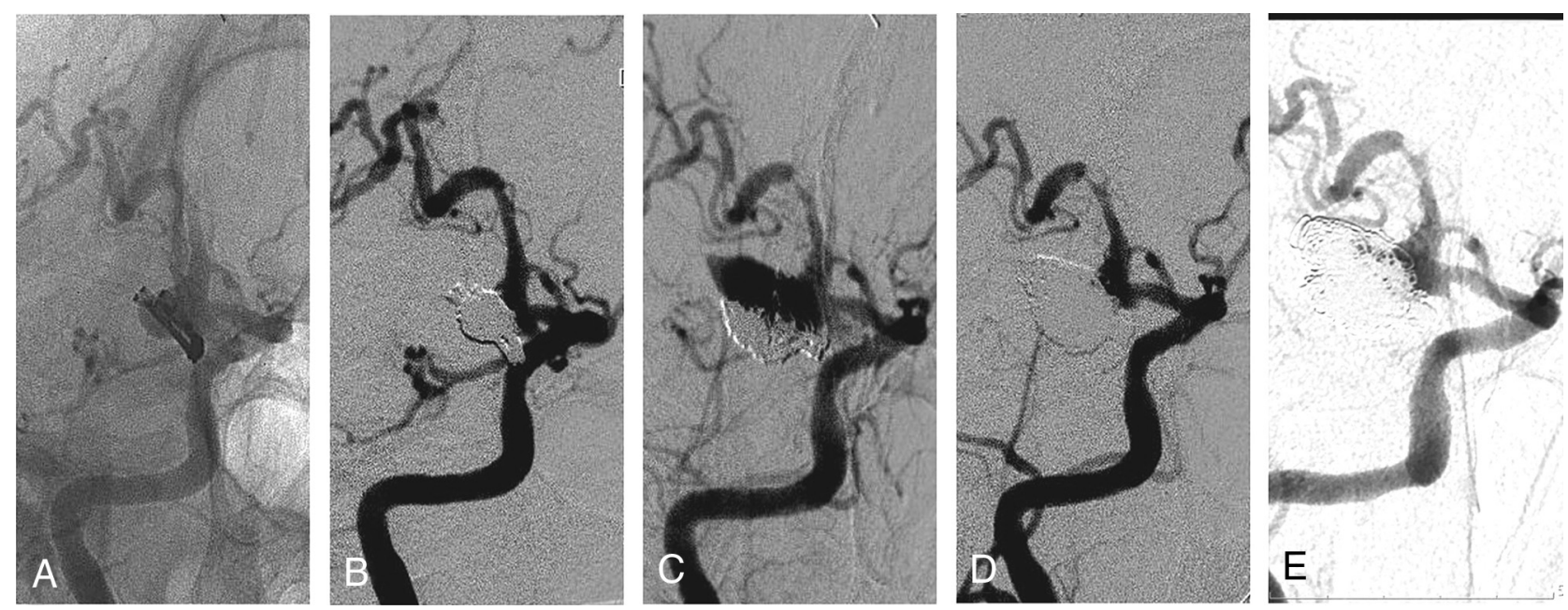

FIG 4. Fourteenth case of our series, posterior communicating artery aneurysm. A, Working angle view angiography before the first coil embolization. B, After the first coil embolization, the final angiography evaluation reveals the residual neck of the aneurysm. $C$, After $18 \mathrm{months}$, follow-up angiography reveals major recurrence of the aneurysm. $D$, After the second coil embolization, a residual neck is detected in the final angiography evaluation. $E$, Follow-up angiography reveals minor recurrence.
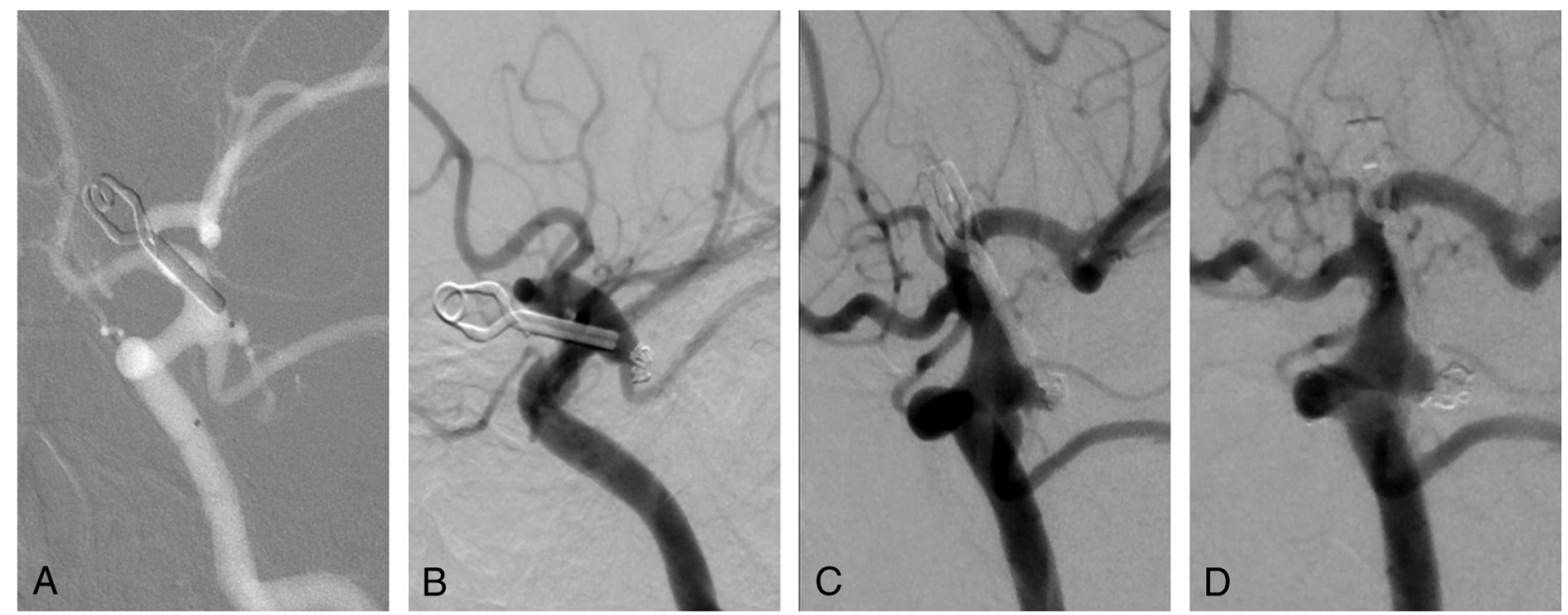

FIG 5. Sixteenth case of our series, posterior communicating artery aneurysm. A, Working angle view angiography before the first coil embolization. $B$, After the first coil embolization, the final angiographic evaluation reveals the residual neck of the aneurysm. $C$, After 47 months, follow-up angiography reveals major recurrence of the aneurysm. $D$, After the second coil embolization, the final angiography evaluation reveals complete occlusion of the aneurysm.

Table 2: Characteristics and treatment results of recurrent aneurysms after coil embolization

\begin{tabular}{llcccccccc}
\hline No. & Location & $\begin{array}{c}\text { Presentation } \\
\text { at Clipping }\end{array}$ & $\begin{array}{c}\text { Presentation } \\
\text { at Coiling }\end{array}$ & $\begin{array}{c}\text { Interval to } \\
\text { Retreatment }\end{array}$ & $\begin{array}{c}\text { Size } \\
(\mathbf{H} \times \mathbf{W}) \\
(\mathbf{m m})\end{array}$ & $\begin{array}{c}\text { Neck } \\
\text { Diameter } \\
(\mathbf{m m})\end{array}$ & $\begin{array}{c}\text { Immediate } \\
\text { Radiologic } \\
\text { Results }\end{array}$ & $\begin{array}{c}\text { Reason for } \\
\text { Recurrence }\end{array}$ & $\begin{array}{c}\text { Follow-Up } \\
\text { mRS }\end{array}$ \\
\hline 1 & PcomA & $\mathrm{R}$ & $\mathrm{R} /-/-$ & $41 / 43 \mathrm{mo}$ & $8.7 \times 6.3$ & 5.1 & $\mathrm{C} / \mathrm{N} / \mathrm{N}$ & $\begin{array}{l}\text { Regrowth } \\
\text { Regrowth }\end{array}$ & 0 \\
8 & Basilar tip & $\mathrm{R}$ & $-/-$ & $29 \mathrm{mo}$ & $3.8 \times 7.2$ & 6 & $\mathrm{C} / \mathrm{N}$ & 0 \\
13 & MCA & $\mathrm{R}$ & $\mathrm{R} / \mathrm{R}$ & $180 \mathrm{mo}$ & $12 \times 10$ & 10 & $\mathrm{~N} / \mathrm{C}$ & Regrowth \\
14 & PcomA & $\mathrm{R}$ & $\mathrm{R} / \mathrm{R}$ & $18 \mathrm{mo}$ & $7.8 \times 8.1$ & 8.1 & $\mathrm{~N} / \mathrm{N}$ & Regrowth & 4 \\
16 & PcomA & $\mathrm{R}$ & $\mathrm{R} /-$ & $47 \mathrm{mo}$ & $3.3 \times 3.0$ & 2.4 & $\mathrm{~N} / \mathrm{C}$ & Regrowth & 0 \\
\hline
\end{tabular}

Note:-C indicates complete occlusion; $\mathrm{H}$, height; $\mathrm{N}$, residual neck; $\mathrm{R}$, ruptured; $\mathrm{W}$, width.

cal clipping were $41.7 \%(5 / 12)$ and $16.6 \%(2 / 12)$, respectively. These rates are high compared with the general consensus and previous reports. ${ }^{1-5}$ This finding may be because our series included only recurrent aneurysms after surgical clipping, unlike previous reports that examined recurrent and residual aneurysms after surgical clipping. Due to the high recurrence and rebleeding rates, strict follow-up with conventional angiography should be mandatory after coil embolization of recurrent cerebral aneurysms treated by surgical clipping.

Aneurysm regrowth is thought to be an aggressive angiographic characteristic that may be more susceptible to recurrence after repeat endovascular coiling than after coil compaction. ${ }^{11,12}$ In our series, all the aneurysms that recurred after coil embolization showed a tendency toward regrowth rather than coil com- 
paction. Furthermore, the recurred aneurysms after coil embolization showed repeat recurrence of up to 3 times, and some aneurysms are currently still growing. These aneurysms seem to have more aggressive characteristics than the usual cerebral aneurysms. Accordingly, simple coil embolization without flow diversion in most of our patients $(n=17,89.5 \%)$ showed limited treatment potential in terms of durability for the aneurysms that showed regrowth because this method may not be able to recover the pathologically altered part of the vessel wall adjacent to the aneurysm, potentially leading to regrowth of the aneurysm.

Accordingly, it would be better to consider aggressive treatment options for recurrent cerebral aneurysms after surgical clipping unless the treatment option might increase the patient's risk considerably. Providing flow-diversion effects such as stent-assisted coiling or a flow diverter rather than simple coiling might improve the durability of the treatment for recurrent cerebral aneurysms that were initially treated by surgical clipping. In fact, we observed favorable outcomes using a flow diverter for recurrent cerebral aneurysms after surgical clipping or endovascular coiling. ${ }^{13,14}$ Furthermore, the stents intended for stent-assisted coiling but not for flow diversion also have a certain flow-diversion effect. ${ }^{15-17}$ However, those results were based on relatively short-term results or observed in an experimental environment such as with computational fluid dynamics simulation. Accordingly, we should consider the technical feasibility of applying flow diversion in each patient individually when treating this kind of lesion.

This report is a retrospective study of data from patients who underwent coil embolization at 2 centers and does not include surgical results. The study also has a small sample size and a relatively low rate of follow-up angiography after coil embolization. Therefore, the inability to obtain statistically significant results for all data analyzed is a limitation of this study.

\section{CONCLUSIONS}

In our series, coil embolization of recurrent aneurysms after surgical clipping was feasible but resulted in a high recurrence rate. Aneurysm regrowth rather than coil compaction was a major factor in the recurrence of cerebral aneurysms in this series. Strict imaging follow-up is required after coil embolization of these lesions due to the high recurrence and rebleeding risks.

\section{REFERENCES}

1. Chung J, Park IS, Park H, et al. Endovascular coil embolization after clipping: endovascular treatment of incompletely clipped or recurred cerebral aneurysms. J Cerebrovasc Endovasc Neurosurg 2014; 16:262-67 CrossRef Medline
2. Kim BM, Kim DJ, Kim DI, et al. Clinical presentation and outcomes of coil embolization of remnant or recurred intracranial aneurysm after clipping. Neurosurgery 2010;66:1128-33; discussion 1133 CrossRef Medline

3. Kim ST, Jeong HW, Jeong YG, et al. Coiling as retreatment in intracranial aneurysm of de novo formation or regrowth: case report. Neurointervention 2013;8:46-51 CrossRef Medline

4. Rabinstein AA, Nichols DA. Endovascular coil embolization of cerebral aneurysm remnants after incomplete surgical obliteration. Stroke 2002;33:1809-15 CrossRef Medline

5. Schaafsma JD, Sprengers ME, van Rooij WJ, et al. Long-term recurrent subarachnoid hemorrhage after adequate coiling versus clipping of ruptured intracranial aneurysms. Stroke 2009;40:1758-63 CrossRef Medline

6. Raymond J, Guilbert F, Weill A, et al. Long-term angiographic recurrences after selective endovascular treatment of aneurysms with detachable coils. Stroke 2003;34:1398-403 CrossRef Medline

7. Roy D, Milot G, Raymond J. Endovascular treatment of unruptured aneurysms. Stroke 2001;32:1998-2004 CrossRef Medline

8. Hokari M, Kazumara K, Nakayama N, et al. Treatment of recurrent intracranial aneurysms after clipping: a report of 23 cases and a review of the literature. World Neurosurg 2016;92:434-44 CrossRef Medline

9. Kobayashi S, Moroi J, Hikichi K, et al. Treatment of recurrent intracranial aneurysms after neck clipping: novel classification scheme and management strategies. Oper Neurosurg (Hagerstown) 2017;13: 670-78 CrossRef Medline

10. Park HK, Horowitz M, Jungreis C, et al. Periprocedural morbidity and mortality associated with endovascular treatment of intracranial aneurysms. AJNR Am J Neuroradiol 2005;26:506-14 Medline

11. Hasan DM, Nadareyshvili AI, Hoppe AL, et al. Cerebral aneurysm sac growth as the etiology of recurrence after successful coil embolization. Stroke 2012;43:866-68 CrossRef Medline

12. Hoppe AL, Raghavan ML, Hasan DM. Comparison of the association of sac growth and coil compaction with recurrence in coil embolized cerebral aneurysms. PLoS One 2015;10:e0123017 CrossRef Medline

13. Ding D, Starke RM, Evans AJ, et al. Endovascular treatment of recurrent intracranial aneurysms following previous microsurgical clipping with the Pipeline Embolization Device. J Clin Neurosci 2014;21:1241-44 CrossRef Medline

14. Dornbos D, Karras CL, Wenger N, et al. Pipeline embolization device for recurrence of previously treated aneurysms. Neurosurg Focus 2017;42:E8 CrossRef Medline

15. Wang C, Tian Z, Liu J, et al. Flow diverter effect of LVIS stent on cerebral aneurysm hemodynamics: a comparison with Enterprise stents and the Pipeline device. J Transl Med 2016;14:199 CrossRef Medline

16. Choi HH, Ha EJ, Lee JJ, et al. Comparison of clinical outcomes of intracranial aneurysms: procedural rupture versus spontaneous rupture. AJNR Am J Neuroradiol 2017;38:2126-30 CrossRef Medline

17. Tremmel M, Xiang J, Natarajan SK, et al. Alteration of intra-aneurysmal hemodynamics for flow diversion using Enterprise and Vision stents. World Neurosurg 2010;74:306-15 CrossRef Medline 